Journal of NELTA Gandaki (JoNG), III (1 \& 2), 25-35

ISSN 2676-1041 (Print)

DOI : https://doi.org/10.3126/jong.v3i1-2.33142

\title{
Students' Views on Shadowing in English Language Learning
}

Dr. Arun Kumar Kshetree

Article History: Received May 6, 2020; Revised August 17, 2020; Accepted October 1, 2020; Online Published November 2020.

To cite this article: Kshetree, A. K. (2020). Students' views on shadowing in English language learning. Journal of NELTA Gandaki (JoNG), III (1\&2), 25-35. DOI : https://doi.org/10.3126/ jong.v3i1-2.33142

\begin{abstract}
This article is a part of a mini-research conducted in Rupandehi district, Tilottama municipality to find out the situation of shadowing in education and its effect in English language learning. It focuses on the students' views towards shadowing to learn English. Though the study was conducted there in two private schools of the municipality, the participants were from various districts and have passed SEE from different government and private schools of Lumbini region and outside. The results found include that the students are spellbound in taking part in shadow activities of education and they believe that whatever they achieved was due to shadowing not due to the regular classes. The study also reveals some unwanted activities of the teachers involved in shadow activities like giving clues of questions to prepare the exams, helping students in exam halls and so on.
\end{abstract}

Keywords: ELL, shadowing, tuition classes, home tuition, coaching classes

\section{Introduction}

English has been a very important language to survive in the $21^{\text {st }}$ century world. It is taught as compulsory paper from the beginning of the school education to master degree in Nepal. English language teaching in Nepal does not have a long history and the society believes that the English language teaching and learning in Nepal is not successful in the real sense (Kshetree, 2018). The formal teaching of English in the schools is especially much criticized as the students have to take tuition or get admitted in the coaching centres for the preparation of the decisive final examinations of English. The students are compelled to join different tuition centres and private tutors only to be able to pass the examinations and are compelled to pay much more than they pay for the formal education in their schools. Taking tuition has almost been a culture even in the good boarding schools although they are called English medium schools. (Kshetree, 2019) Thus, the practice of getting involved in academic activities, apart from the formal school teaching and learning has been common in Nepal as well.

Private tutoring, taking coaching classes or getting home tutors have been widely known as shadow education. Different forms of imparting education to the students out of the formal school or college situations are termed as shadow education. Bray (2010) describes that the label 'shadow education' is appropriate for several reasons. First, private supplementary tutoring only exists with the mainstream education system; second, as the size and shape of the mainstream system change, so do the size 
and shape of supplementary tutoring; third, in almost all societies much more attention focuses on the mainstream than on its shadow; and fourth, the features of the shadow system are much less distinct than those of the mainstream system. Shadow education takes different forms in different cultures. (p. 13)

This trend of taking private tuition has clear implications for efforts to achieve equity in access to education and high levels of learning for all. However, equalization of access to schooling alone, in the absence of good quality teaching and learning, is not enough. Access without quality along with parents' wishes to give their children every advantage that they can, are key reasons for the growth in uptake of private tuition. Of note, parents of all socioeconomic levels are striving to provide their children with extra tuition. In some cases, this supplements attendance at government schools, which may be a cheaper option than sending a child to private school; while in other cases it is in addition to private school attendance, including attendance at private schools of all fee levels. It is important to gain an understanding of growth in private tuition, including an understanding of the profile of students who take private tuition and the reasons for this.

Private tuition as a major activity of shadowing can thus be described as fee-paying supplementary education that students take with the motivation to acquire subject knowledge to increase their educational chances in the formal system of education. Particularly, lots of secondary level school students use it in order to succeed in the final board examinations that determine successful completion of schooling, as well as university entrance and ultimately chances of gaining government employment. Private tuition, referred to by Bray (1999) as the 'shadow education' system, is a fee-based educational service, and can be provided by different types of service providers. The services are closely linked to the formal education system, aimed at helping students to meet its curriculum requirements. Private tuition is often provided by individuals, from secondary school pupils, university students, graduates and qualified teachers, to organized businesses and even chain businesses. It has gone from being seen as just a source of supplemental income for an educated (often young) person, to being a business in its own right, part of what is now a large-scale industry (Bray 1999). Increasing supply and demand each seem to be feeding growth in the other, and there is supply to meet all types of demand from the relatively poor who can still pay something, to the very wealthy. In addition, while tuition traditionally has consisted of a tutor and anywhere from one pupil to many, the internet has enabled distance (online) tutoring, where a reliable internet connection is available.

Shadowing in education was common in the past in Nepal specially, the well-to do families would hire home tutors for their children and other students would join the coaching classes with many other students. Bray (2013) further points out that the history of private supplementary tutoring is probably as old as the history of formal schooling. The notion of seeking extra help for children and youths to help them to keep up with peers and/or to stretch their learning further is thus longstanding. However, in earlier decades and centuries supplementary tutoring was modest in scale, chiefly confined to relatively prosperous households. In the contemporary era, shadow education reaches a much wider spectrum of income groups and has become a major phenomenon around the world. Likewise, Stevenson and Baker (1992) defined shadow education as a set of educational activities outside formal schooling that are designed to improve a student's chances of successfully moving through the allocation process. In the past, the extensive use 
of shadow education was only observed in a few countries, especially in several East Asian countries. However, recent research shows that the expansion and prevalence of shadow education is a worldwide phenomenon, and shadow education is one of the fastest growing industries in many countries around the world.

This is because in most cases, shadow education accompanies significant private capital investment on the part of certain families and, at the same time, it is less feasible for many families with limited economic capital (Baker and Le Tendre, 2005). In the same way, Grodsky (2010) points out that shadow education is different from other mechanisms that contribute to educational inequality such as school segregation and tracking or ability grouping within schools that fall under the control of educational organizations. That is, it is more difficult to control the pervasiveness and repercussions of shadow education compared to other factors since it takes place outside of formal schooling. Bray (2006) mentions that some countries such as South Korea, Uganda and Mauritius have tried to ban shadow education, but the ban was ineffective. Along these lines, if shadow education does make a difference in academic achievement, it carries important implications concerning educational opportunity and stratification in society. It is obviously a mechanism for maintaining and increasing social stratification by conferring educational advantages on students who are already advantaged in terms of their rich economic, social and cultural capital.

In case of Nepal, the private tutoring was very a common phenomenon. The education system in the traditional Nepal was simply home based teaching which was inspired by Hindu philosophy that they called Gurukul Shikshya (Kshetree, 2019). Thus, before formal school education system was started there was the culture of getting education from some educated well-known Gurus. This shows that the shadow education started in Nepal very long ago. During the Rana regime as well the common people were educated by home based tutoring and even Rana's children also used to be taught in their palaces not in the schools. Later on only the establishment of Durbar School opened the chances to go to school specially for the children of Ranas. As the Rana regime was over, the schools were in various places and common people's children started to go to schools (Rana, 2012). However, as some of the courses were difficult for the students they started to get private tutoring, joining coaching classes or even hiring a home based tutor for their support in the subjects they feel difficulty. This system is going on until now. When the students feel that they are close to the School Leaving Certificate, SLC (now School Education Examination, SEE) examination, they start taking tuition, joining coaching classes in their schools and other institutions. It has become a fashion like activity to get tuition classes from beginning of the school especially to complete the homework of the students. Thus, the system of shadow education has been a fashion among the students and parents. The parents who do not have time to help their children's study and those who cannot help their children in their studies and those who cannot help them in completing their homework are compelled to send their children to take tuition or hire a home tutor. Such phenomenon has been proved fruitful to them as their problem is solved.

The point here is that English was supposed to be very difficult in the rural Nepal and the parents used to be compelled to manage private tutoring to their children so that they could easily pass the SLC exam in the past and SEE exam these days. All the children became very happy to have tuition or 
coaching classes apart from their regular school classes. It became a fashion among the children in Nepal. Many parents and children think that it certainly increases their marks in the exam results' and helpful in increasing the English achievement of the children. In this backdrop, a study was planned to analyse the effect of shadowing in the achievement of students in English. The main objective of the present study is to analyse the role of shadow education in the English language learning in Nepal. I thought that the study will be significant for the policy makers and general practitioners to systematize the shadow activities in education. It will also be helpful for the teachers and students as it will try to show the impact of shadow activities in English Language Teaching (ELT).

There is very limited research conducted in Nepal in this area and some researches completed in this area in other parts of the world try to analyse the shadowing in education and its various aspects. A research was conducted by Sujatha (2007) for United Nations Educational, Scientific, and Cultural Organization (UNESCO) and reported that a strong presence of private coaching classes was observed in Kerala and a low presence in Andhra Pradesh in India. The relationship between school and the shadow institution of education has manifested the tensions between form and function in a distinct and interesting way. This report concludes that though there is tension between the schools and the shadowing institutions, the schools were also accepting the roles of such institutions. The shadowing in education is blended in the formal education from the establishment of education bodies and schools.

In Sri Lanka, the shadowing activities of education are forcing the parents to invest more in the education of their children. This has increased the total household expenditure there and the investment in education. A research in Sri Lanka, conducted by Pallegedara (2011) showed that expenditures there were rising over time. Referring to national household surveys, the researcher noted that in 1995/96, 23.3\% of households with school-aged children spent money on private tutoring, and $14.8 \%$ of households allocated $1 \%-5 \%$ of total household expenditure for tutoring. In 2006/07, $64.0 \%$ of households spent money on private tutoring, and $24.0 \%$ allocated $1 \%-5 \%$ of total household expenditure for tutoring. Moreover, some households spent even more. In 2006/07, 2.7\% of households allocated between $5 \%$ and $10 \%$ of their total expenditures for private tutoring, and $0.9 \%$ allocated more than $10 \%$. The situation of Nepal is also being similar regarding this issue.

Examining correlations between receipt of tutoring and scores of 22,500 students on the grade 10 School Leaving Certificate examination, Thapa, (2011) found that students in public schools who had received tutoring had higher scores by 1.74 percentage points. However, no significant difference was found for students in private schools. This study shows the increment of students' scores after their involvement in the shadowing activities like joining the tuition. Likewise, in the case of Malaysia, Jelani and Tan (2012) looked at patterns of private tutoring received by primary school students in Penang, which concluded that students of Chinese ethnicity were more likely to receive tutoring, observing that such students formed $38 \%$ of the population but $46 \%$ of students in their sample. By contrast, Malays formed $51 \%$ of the population but only $44 \%$ of their sample. This means that the private tutoring like shadowing activities are common not only in developed and under developed countries but also common everywhere around the world, even in the people's republic of China, a communist governing country. Although there 
are many research works accomplished in various aspects of shadow education, there is no any evidence of researches conducted in Nepal related to the present study. There are some studies conducted related to privatization of education with shadow education and like this.

In this foundation the researcher tried to study the impact of shadowing activities in English language teaching and learning. This article focuses on the students' views on shadowing activities in their achievement of English specially focusing on the SEE/ SLC examination results. The students' views regarding the help from their tutors not only in studies and higher achievements in English but also in the preparation of examinations were also a part of the study.

\section{Methodology}

This study is a part of a survey research conducted with the support of research centre of TU in 2019. For this study, I have purposively selected the case of 20 students studying in grade 11 from Tilottama Campus and other 20 students of the same level from New Horizon School. Thus, the participants were studying in grade 11 in the Tilottama Municipality, Rupandehi. I selected two best schools of the locality because the students scoring higher in the SEE could be found there. I developed a set of questionnaire to gather information from the students and used the same for the purpose of gathering information required. With the tools, I visited the authority of the schools such as the principal and the subject teachers to get permission to visit and gather information from the students of their schools. I visited the students in a separate room where I described them about the purpose of my study in detail and requested them to fill the questionnaire. I also assured them that the information will not be misused for any other purposes except for this research report preparation. With this commitment, the students wrote their responses in the paper provided and I gathered the information required for this study. The gathered data were analyzed and interpreted using simple statistical tools like mean, average and tables, diagrams and graphs, some of which are presented in this article.

\section{Results and Discussion}

A questionnaire was distributed to the students to investigate their views about the importance of shadow activities in education. The questionnaire was to be filled out by the respondent students. A question was asked to find out the students' scores in English and the trend of their English scores, which is presented in figure 1 .

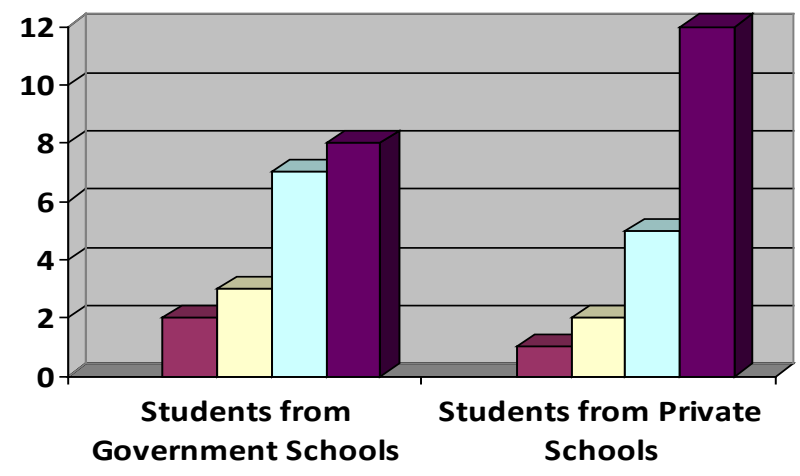

$\square$ Scores below $70 \%$
$\square$ Scores upto $80 \%$
$\square$ Scores between 80 to $85 \%$
$\square$ Scores above $85 \%$




\section{Figure 1: Students' Scores in English in SEE}

As the selection was made by searching brighter students from different government and private schools who were studying in the two schools of Rupandehi, the scores in English were found to be high. 12 out of 20 students were found to have secured more than 85 percent in English whereas only 8 students from the government schools have secured similar scores. The number of students securing less than 70 percent scores was too less; only one from private school and two from government school reported that they had less than 70 percent scores in English.

In the same way, a question was asked to find out the English results of the students during the tenth grade, which is presented in table 1

Table 1

Students' English Results in Tenth Grade

\begin{tabular}{lllll}
\hline S. N. & Students & Government Schools & Private schools & Remarks \\
\hline 1 & Who used to pass tests & 12 & 10 & \\
2 & Who used to fail tests & 8 & 10 & \\
\hline
\end{tabular}

Table 1 shows that the students used to fail the class tests and internal exams in their schools especially in grade ten. Sixty percent of the students studying in government schools reported that they failed some tests and exams during their tenth grade study whereas only fifty percent of the students said they were also failed in class tests and exams during the same time.

Likewise, two questions were asked to the students about their views regarding their scores in English and their regular classes in their schools. The findings are presented in table 2.

Table 2

Students' Views about the English Scores and Classes

\begin{tabular}{lllll}
\hline S. N. & Students & $\begin{array}{l}\text { Good English due to } \\
\text { school classes }\end{array}$ & $\begin{array}{l}\text { School classes } \\
\text { sufficient }\end{array}$ & $\begin{array}{l}\text { Main credit for } \\
\text { present English }\end{array}$ \\
\hline 1 & $\begin{array}{l}\text { From government } \\
\text { schools }\end{array}$ & No & No & Tuition/ coaching \\
2 & From private schools & No & No & Coaching / Tuition \\
\hline
\end{tabular}

Table 2 shows that the students from both schools reported that the development of their English was not developed due to their regular classes. All the students in my sample reported that the regular school classes were not sufficient for them to improve their English properly. Not only this, the students of government and private schools said that the main credit for their high scores in English in the SEE exam was given to the tuition classes they studied and the coaching classes they attended during their tenth grade. This indicates that the students think that their school classes were ineffective and insufficient to improve English by scoring higher marks.

Regarding their activities to improve their English and increase their scores in English, they responded in the following ways: 


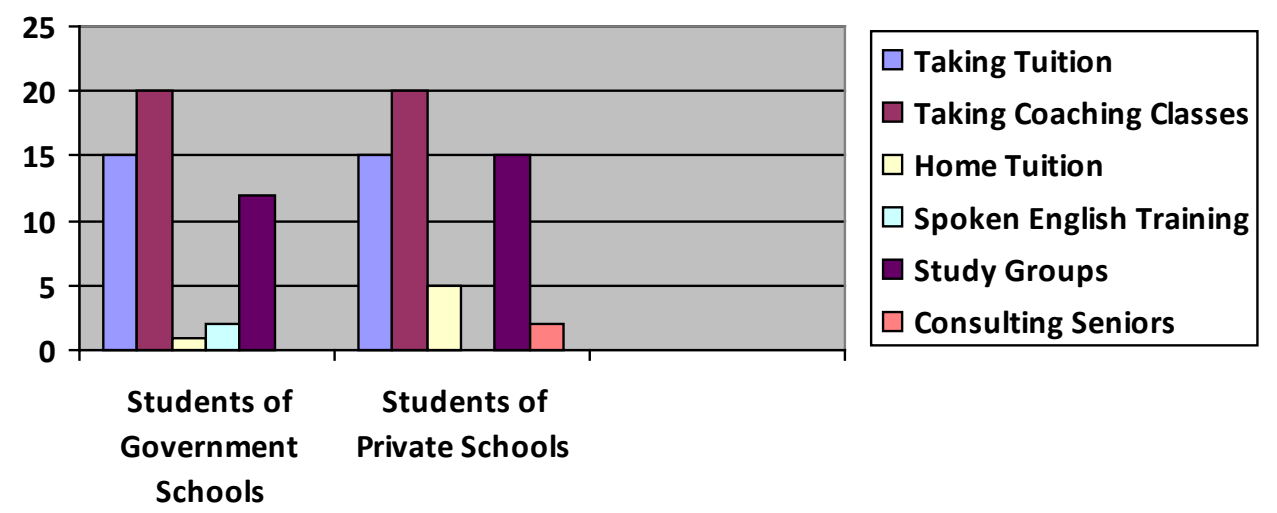

Figure 2: Students' Shadow Education Activities in English

Figure 2 shows the number of the students taking tuition was higher in private schools as it shows that 75 percent of the students were involved in general tuition classes and rest 25 percent of them were taking benefit from home tuition. However, 80 percent students from the government schools reported that they were involved in the tuition classes to increase their scores in English. All the students said that they took coaching classes, which might be because of the fact that it was compulsory in the schools. Only two students from the government school said that they joined spoken English classes to improve English.

Table 3 shows that 60 percent of the students in government schools worked in the study groups for the preparation of the exams and 75 percent of the students of private schools did the same. Two students of the private school students were found to have consulted seniors for their development. Collecting notes of toppers, photocopying the useful materials related to English were some other activities of the students for the development of English.

There were some questions in the questionnaire related to the attitudes of students towards shadow activities of education basically to find out how they feel about the activities and their beliefs. Table 3 presents their views related to their attitudes towards shadowing in education.

Table 3

Students' Attitudes Towards Shadow Activities

\begin{tabular}{llll}
\hline S N & Particulars & $\begin{array}{l}\text { Government } \\
\text { School Students }\end{array}$ & $\begin{array}{l}\text { Private School } \\
\text { Students }\end{array}$ \\
\hline 1 & Studying with the same teacher & 19 & 15 \\
2 & Cause of selection of the teacher & Support from the teacher & Teacher is famous \\
3 & Get help from the teacher during exam & 5 & 8 \\
4 & Get clues about questions asked in the exam & 10 & 14 \\
5 & Suggest juniors to take tuition & 18 & 20 \\
\hline
\end{tabular}

Table 3 describes the attitudes of the students towards the shadow activities in education. It shows that almost all the students of government schools (i.e. 19 out of 20) have taken tuition from the same teacher who used to teach them in their schools whereas 75 percent of the students from the private schools 
were found to have taken tuition classes from the teachers who used to teach them. The government school students took tuition from them with the hope that they would get support from them in different activities but the students of private schools said that they joined the tuition classes due to the name and fame of the teachers.

Not only this, 25 percent of the students from government schools and 40 percent students from private schools said that they got help from their teachers during examination. Likewise, 50 percent of the government school students said that they got some clues from the teachers about the questions asked in the exam whereas 70 percent of the private school students said that they got some clues about the questions asked in the exam. All the respondents from the private schools replied that they would like to suggest the juniors to take tuition whereas 90 percent of the students of government schools said the same. These evidences show the evidence of the support of the shadow activities in increasing their English scores in the examinations

As the shadowing in education is an inevitable part of our formal education, it seems almost impossible to think about the ways of eliminating it. This study was carried out with the objectives of finding out the contribution of shadow education in ELT and various forms of shadow education.

As the study was conducted selecting better students from the colleges, only twenty percent of the sample students were found to have secured less than 80 percent scores in SEE English exam and 50 percent of the sample students secured more than 85 percent marks in English in the SEE. As Bray (2013) describes there were positive changes everywhere in the students due to the shadowing activities, similar results were found in the present study as well. Sixty percent of the government school students were found to have passed the class tests and internal exams whereas only 50 percent of the students of private schools were passed the tests and internal exams. This indicates that the private school students were encouraged to take the shadow education activities as they were unable to pass the internal exams and after taking tuition or other shadowing they got success in securing better scores in English.

The society keeps blaming the Nepalese education system as being not successful and they blame teachers for not being honest to the students and teaching. All the students of the study sample said that their level of English at present was due to tuition and coaching like shadow activities of education and all of them were in the view that the regular school classes were not sufficient for scoring better and develop English language Proficiency. The similar belief is also reflected in the parents of the students of both government aided and private schools as they are ready to pay for any kind of shadowing activities. All the students in my sample were found to have joined coaching classes whereas 75 percent students from both types of schools were found to have taken tuition classes and one student from government school and five students from private schools were found to have used the facility of home tuition. Two students of government schools were found to have joined spoken English classes with the hope to improve their English. The result seems similar to the conclusions made by Taylor as cited in Bray (2013) that the students give credit to the tuition centers rather than their schools and colleges for their increased marks in the exam and they suggest others to be involved in the shadow activities.

The obtained data also showed that sixty percent of the government school students were found to 
have worked in the study groups whereas seventy five percent of the private school students were found to have studied in the groups. Two of the students from private schools were found to have consulted senior students. This indicates that the socialization part of the students' life can be better by working together in study groups.

Almost all the students (i.e. 19 out of 20) from government schools were found to have taken tuition classes from the same teacher who used to teach them in the school whereas 15 out of 20 students from private schools were found to have studied with the same teacher teaching them in the school. The students from the government school were found to have selected the teacher with the hope to get support in the various activities whereas the student from private schools joined tuition with the teacher who was famous in the locality. Not only this, twenty five percent students of government schools and 40 percent students of the private schools were found to have received support in the exam of English. It was also revealed that fifty percent of the students of government schools and 70 percent students of the private schools were found to have received some clues about the questions asked in the exam from their tuition teachers. The facts in this point clearly prove that the teachers themselves are not honest in the class and they always encourage the students to take tuition or coaching like activities. The examples of their unethical behaviors are not worth discussing in detail. The situation is not only in Nepal, Bray (2013) quotes Sujatha who describes the situation of Kerala, India where 98\% students take tuition in Mathematics. In different parts of the world the shadowing activities are very common. The students studying in different kinds of schools take tuition for various reasons for example to reduce the stress of assignments of the class. Bray (2013) presents many research conclusions related these facts.

Almost all the students from private schools and 90 percent students of government schools were found to be suggesting juniors to join tuition or coaching to improve English and to increase the English scores in SEE. The students suggesting their juniors to take tuition and coaching like shadowing activities show that the belief of the students towards the formal classes is decreasing and their dependency towards shadowing is increasing. This is not a positive sign towards our education system. .

\section{Conclusion and Implications}

By the analysis of the data obtained from the students involved in taking tuition classes like shadowing activities, some conclusions regarding the benefits of shadow education activities can be presented. Though the shadow education activities are of different types in other parts of the world, in case of Nepal, the most common activities related to shadowing are taking tuition, hiring home tutor, joining coaching classes and joining spoken English classes, etc. The students believe that the regular classroom activities are not sufficient for their proper development. Most of the high scorer students said that their scores were due to the tuition classes and coaching classes not just because of the regular classes of the school. Many students believed that they get some help by their tuition teachers during the exam as well which is completely unethical.

The shadow education is very common not only in developing countries like Nepal, but also in developed countries. Various activities related to shadow education are commonly used by the students to 
increase their marks and to improve their English language competency and basically the English scores in the decisive examinations. Thus, the role of shadowing in education is really helpful in achieving better scores in the decisive examinations like SEE and $12^{\text {th }}$ grade final examinations. The findings also indicate the bitter reality of the Nepalese education system where the students do not give credit to the regular school classes for whatever they have achieved and scored in the examinations. The government has been investing a huge amount of the national budget for the education of the children and training and development of the teachers. But the students are not ready to accept whatever they achieved was due to the school. The policy makers of education system need to be serious about this matter and design the schooling phenomena in such a way that the students and parents do not have to bother about their studies once they enroll into a school. The things expressed about the teachers' help and support to the students who took tuition with them is also not a good activity for an ideal teacher, which also needs to be addressed by the practitioner teachers. Not only this, the same teacher cannot make the students understand in the school class but the same teacher makes them satisfied in the tuition centre seems funny but serious for the policy making authority. The policy makers need to be serious to improve the ELT situation at least by addressing these issues as well. These issues may require further researches in large scale but should not be discarded as normal activities.

\section{References}

Baker, D., \& Le Tendre, G.K. (2005). National differences, global similarities: World culture and the future of schooling. Stanford: Stanford University Press.

Bray, M. (1999). The shadow education system: private tutoring and its implications for planners. Fundamentals of Educational Planning 61, Paris: UNESCO

Bray, M. (2006). Private supplementary tutoring: comparative perspectives on patterns and implications. Compare: A Journal of Comparative Education, 36(4), 515-530.

Bray, M. (2010). Researching shadow education: methodological challenges and directions. Asia Pacific Education Review, 11(1), 3-13.

Bray, M. (2013). Benefits and tensions of shadow education: Comparative perspectives on the roles and impact of private supplementary tutoring in the lives of Hong Kong students'. Journal of International and Comparative Education: 2 (1).

Grodsky, E. (2010). Commentaries: Learning in the shadows and in the light of day. Social Forces.

Jelani, J. \&. Tan, A. K. G. (2012). Determinants of participation and expenditure patterns of private tuition received by primary school students in Penang, Malaysia: An exploratory study. Asia Pacific Journal of Education, 32(1), 19-35.

Kshetree, A. K. (2019). Shadow education and its impact on ELT in Nepal: A case of Tilottama Municipality, Rupandehi ( mini research report, Centre for Research) Tribhuvan University, Nepal.

Kshetree, A. K. (2018). Policies, practices and prospects of basic school English teacher training in Nepal (unpublished Ph.D. dissertation) Faculty of Education, Tribhuvan University, Nepal.

Pallegedara, A. (2011). Demand for private tuition classes under the free education policy: Evidence 
based on Sri Lanka. Munich: Munich Personal RePEc Archive. Retrieved from http://mpra.ub.unimuenchen.de/31969/1/MPRA_paper_31969.pdf

Rana, S.P.J.B. (2012). Foundation of education. Kathmandu: Vidyarthi Pustak Bhandar.

Stevenson, D. L. \& Baker, D. P. (1992). Shadow education and allocation in formal schooling: transition to university in Japan. American Journal of Sociology, 97 (6), 1639-1657.

Sujatha, K. (2007). Private tuition in India: trends and policy implications. Paper presented at the IIEP Policy Forum on Confronting the shadow education system: what government policies for what private tutoring? Paris: IIEP-UNESCO.

Thapa, A. (2011). Does private school competition improve public school performance? The case of Nepal (unpublished Ph. D. dissertation).Graduate School of Arts and Sciences, Columbia University.

Dr. Arun Kumar Kshetree is a lecturer at Tribhuvan University, Butwal M. Campus. He has published articles in different journals and edited journals. He has presented papers in national and international forums and facilitated many local and national teacher training sessions on Teaching English and Professional Development. His major areas of interest include language teaching, research and teachers' professional development. 